\title{
Location-Aware Mobile Learning Model: A Case for Positioning Performance Measurements
}

\author{
Mohammad Alnabhan ${ }^{1}$, Nasim Matar ${ }^{2}$, Abdulameer Hussain ${ }^{1} \& \mathrm{Ja}^{\prime}$ afer AL-Saraireh ${ }^{3}$ \\ ${ }^{1}$ Jerash University, Jordan \\ ${ }^{2}$ Zarqa University, Jordan \\ ${ }^{3}$ Applied Science University, Jordan \\ Correspondence: Mohammad Alnabhan, Jerash University, Jordan. E-mail: m.alnabhan@jpu.edu.jo
}

Received: February 3, 2014 Accepted: February 24, 2014 Online Published: March 2, 2014

doi:10.5539/cis.v7n2p28 URL: http://dx.doi.org/10.5539/cis.v7n2p28

\begin{abstract}
This research work explores the use of mobile and positioning technologies stimulating a context adaptive and location-based learning model. The proposed model utilizes a set of context factors for learning service dissemination; described as learning service area, learning service type, and service interaction level. In addition, the new model considers the availability of positioning technology for authoring location-based learning content, and for accurately disseminating learning services. Hence, tolerance to position errors is used to classify learning services into two types; generic and specific. An evaluation experiment was conducted measuring the relationship between the positioning performance and successful implementation of the m-learning model. Results have shown a significant affect of position accuracy towards learners' context understanding and interaction with learning activity.
\end{abstract}

Keywords: learning, mobile, location, accuracy, context

\section{Introduction}

Technology advancements support new opportunities for students' engagement in learning activities, and provide new delivery method toward learning resources. The wider adoption of mobile technology in learning environments allows learning to appeal as a continuous and social process, which takes place inside and outside the classrooms. Although of this huge development in the segment of mobile technology, still some user groups with special needs are facing various barriers regarding technological accessibility of use. For example, blind and visually impaired students are not capable to receive same learning information as normally sighted users. Accordingly, learning information and services are required to be designed appropriately to help students with disabilities to overcome accessibility barriers and allow them to benefit from the significant of emergent learning applications. This is achieved by developing context-aware services that considers learners' requirements, capabilities, and preferences (Huang et al., 2008). The increasing availability of positioning technology and its integration with mobile devices has added an additional dimension to the mobile learning context, described as learner's geographical location. This has resulted in new learning scenarios to emerge that allowed the delivery of location-based learning services. Learner's location information is linked to the learning context, and consequently to learning experiences, and thus it allows for social integration during the learning process. This is achieved by utilizing the location information in authoring the learning content and learning services delivery (Rensing et al., 2012).

This paper presents a new learning context adaptation model that takes into consideration a set of factors before service dissemination. Context factors being considered are learning service type, learning service area, and interaction level. The new model is implemented as a location-based learning model, where the use of location information related to learners is considered in learning content authoring and service delivery. As part of context adaption, learning services are classified into two types (generic and specific) based on service sensitivity to errors in context factors determination. Each service type is associated with a positioning performance level to be considered before providing the learning service. This paper is structured as follows; section 2 describes the literature study carried out to conduct this research work; section 3 illustrates the proposed location-based learning model; section 4 provides details of how the proposed model is operating. Section 5 , presents the 
evaluation methodology being conducted and describes the achieved results.

\section{Literature Review}

The impact of integrating educational and capability of mobile technology into learning context was thoroughly investigated in the literature (Fallahkhair et al., 2008, Rensing et al., 2012; Huang et al., 2008). Ubiquitous mobility facilitates learning activity to take place anywhere and allows learners to be connected together through the mobile network (Chen \& Li, 2010). In addition, mobile technology is used to effectively deliver rich learning content during learning activities. The integration of sensing and mobile technologies has been investigated by many researchers, in order to achieve context-aware ubiquitous learning, and to achieve interactive teaching and learning activities. The main advantage of context-aware ubiquitous learning is to support personalized and collaborative knowledge, and allow learners to increase their learning experience, so as to construct personal knowledge (Wu et al., 2012; So et al., 2012). Several studies have considered using the ubiquity of mobile technology in the learning context, improving the accessibility of knowledge to a variety of learning users, including learners with special needs. In Barbieri et al. (2005) an m-learning platform was designed with a set of different system interfaces (vocal, gestural, and tactile), used in order to overcome accessibility barriers for users with different disabilities (blind, visually impaired, deaf, dyslectic students). In addition, learning accessibility using mobile devices was investigated in Ardito et al. (2006), in which CHAT was developed, a software platform that provides adaptable learning services, based on user's preferred way of interacting, as well as the physical context. In Lan et al. (2009), a pedagogical framework was presented utilizing mobile technology in overcoming obstacles in traditional English as a Foreign Language (EFL) and teaching methods. A different m-learning project designed to increase user accessibility, is described as AMobile (Accessible Mobile Learning), which is an online environment for mobile learning with specific features supporting disabled students demolishing barriers experienced in their learning activities (Arrigo \& Ciprì, 2010). Through, AMobile, an empowered multimodal interface system was developed assessing the modality of using mobile devices to support students in their educational activities. The AMobile project considered using the location information of a mobile device supporting the on-site learning experience by providing a vocal navigation service to users.

The use of mobile devices in achieving collaborative, contextual and constructivist mobile learning activities is described in (Jeng et al., 2010). Moreover, this study has considered using mobile embedded GPS devices within the learning environment, in order to bring new opportunities for location or context based learning activities. In the same concern, Rensing et al. (2012) and Sharples et al. (2009) has described how learners can participate in the content preparation process based on their updated location. In which, learners are motivated to use their mobile devices to detect their context and collect location information, and thereby build learning content that fits to the location of the learner. This is more likely described as location-based learning, where educational activities are conducted based on the exploration of a geographical place (Hsiao et al., 2010). ARLearn is an example of location-based learning system supporting mobile content authoring (Ternier \& Börner, 2011). In which, learners are responsible for collecting information and resources related to surrounding objects; such as buildings, houses, monuments or other objects that are present in the nearby environment of learners. This information is used later on constructing learning content or material. A similar location-based learning approach is described in Tan and So (2011), where learners explore specific sites and use mobile and positioning sensor devices to record observations and position coordinates to be used within the learning activity.

The literature has widely addressed the use of mobile and position sensing technologies in the learning context. This includes authoring learning content, learning resources allocation and delivery, as well as learning activity interaction. However, the impact of using positioning technology on the learning performance, and on developing the understanding of learning context has not been previously considered. This work describes the effect of location information accuracy on the efficiency of learning content understanding and service delivery. In addition, this research focuses on increasing learning users' accessibility to knowledge and developing their learning experience, taking into consideration learners' special requirements and service context sensitivity.

\section{Proposed Model Architecture}

As shown in Figure 1, the proposed model architecture consists of two sides; client and server. 


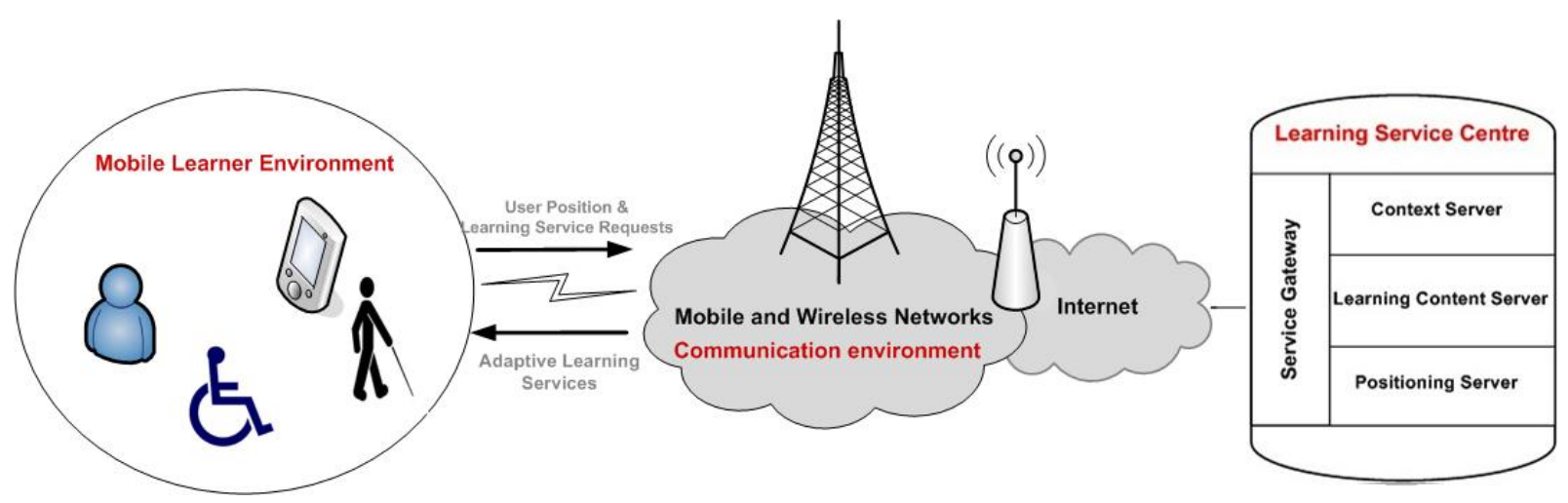

Figure 1. Proposed model architecture

The server side described as Learning Service Centre, holding three main integrated components, the positioning server (responsible for position acquisition and augmentation), context server (responsible for context description and adaption), and content sever (responsible for learning content authoring). The client side represents the Mobile Learner's Environment, which consists of learning users, mobile devices, and surrounding context. Both client and server sides are connected via available mobile and wireless technologies (e.g. 3G, 3.5G, WiFi or WiMAX). Employing a client-server based architecture allows for flexible and adaptive learning services, and provides the following advantages:

- Constructing up-to-date learning materials and provides required services based on the learning context.

- Monitoring and tracks connected learners' location.

- Providing position augmentation services for accurately determining learners' location.

- Ensuring users data privacy and safety.

- Handling different learning users capabilities (e.g. disabled or not-disabled), technical specifications (mobile device specification, GPS receiver type), and learning preferences and style.

\section{Functional Approach}

Figure 2 illustrates the proposed model functional approach, starting from service request and ending with providing adaptive learning services. This approach consists of the following main operational steps:

- Data filtering and interpolation: responsible for data acquisition and classification. Data considered includes specifications of communication technology, learners' location information, and user constrains stored in user profiles.

- Position performance monitoring: measures learners' position fixing accuracy.

- Service interaction monitoring: evaluates level of interaction between learners and learning process, and defines required learning service delivery method.

- Context adaptation and service delivery: allows for providing required learning services, taking into consideration a set of contextual factors including learning service area, learning service type, and service interaction level. 


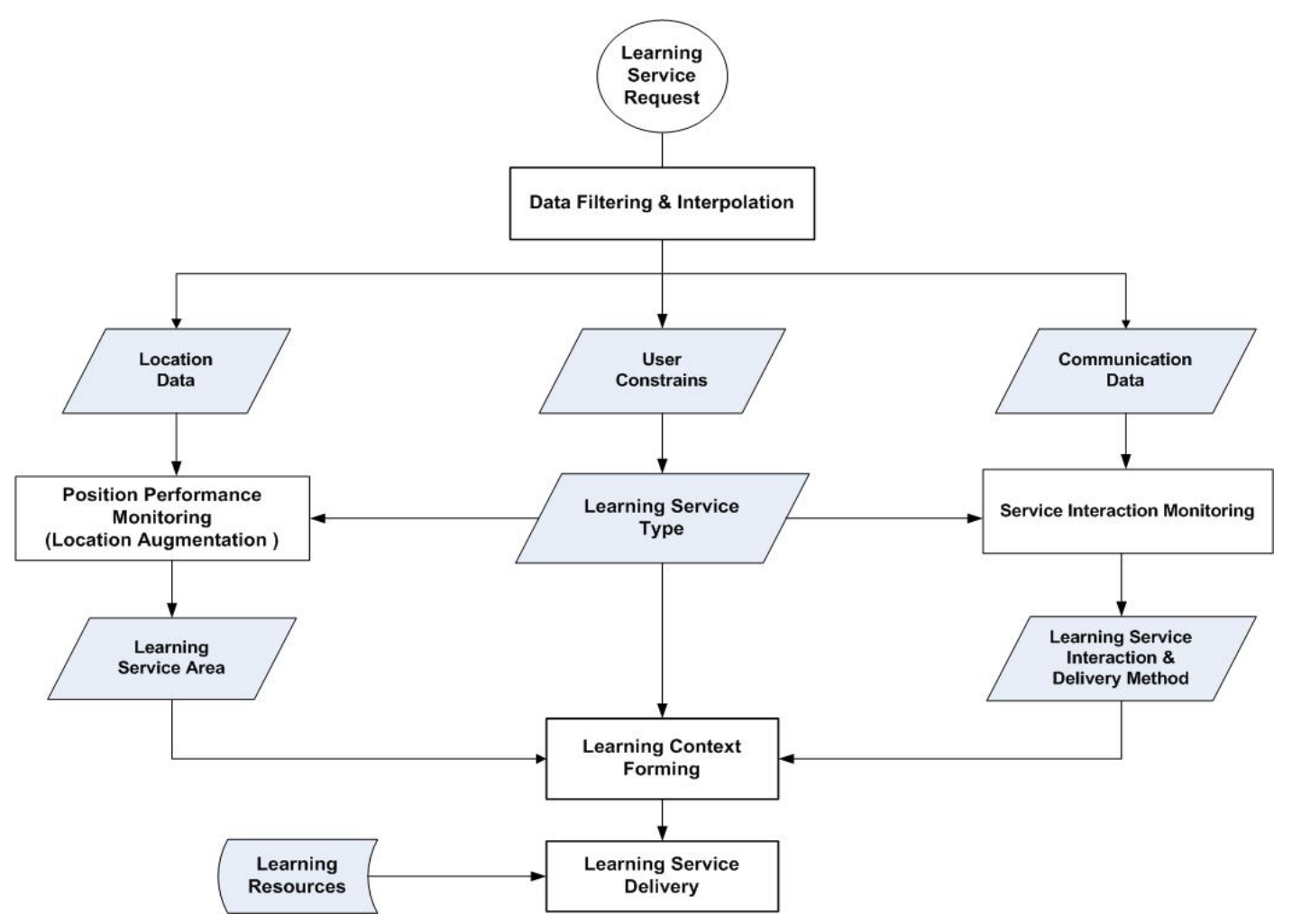

Figure 2. Proposed model functional approach

\subsection{Data Filtering and Interpolation}

User learning requirements can be described in predefined user profiles. Table 1 presents an example of user profiles consisting of three main parameters; learning style, user type and technical specifications. The learning style is used to define suitable learning resources and used to clarify the interaction level between learning service activity and learners. The user type describes users' constrains and defines the sensitivity of learning services. Technical specifications explain details of user's mobile device specifications and communication network being utilized.

Table 1. User profile parameters

\begin{tabular}{ccc}
\hline Learning Style & User Type & Technical Specifications \\
\hline Active - Inactive & All & Mobile Device Specifications \\
Sensing - Intuitive & Special Need & Communication Network Type \\
Visual - Verbal & & \\
Sequential - Sporadic & & \\
\hline
\end{tabular}

In this work, the sensitivity of learning services is measured according to service error tolerance level. As described earlier, the focus of this work is on location-based learning services; hence errors being considered are in position or context determination and on learning content delivery. As described in Table 2, error tolerance is used to differentiate learning services into two types; generic and specific.

Table 2. Learning service types vs user types

\begin{tabular}{cc}
\hline Learning Service Type & User Type \\
\hline Generic (error tolerance) & All \\
Specific (non-error tolerance) & Special Need (e.g. disabled) \\
\hline
\end{tabular}


Generic learning services are described as secondary and complementary services and can be focused towards all types of users. Hence, generic services can accept or tolerate errors. Specific learning services are described as crucial services with high priority, and normally associated with users having special needs. Therefore, specific services are sensitive to errors. Examples of specific services are learning activities dealing with disabled learners (e.g. synthesized lecturing, campus guidance, surrounding objects alerting). In addition, learning services requiring real-time action (e.g. exams and schedule alerting) can be considered with high priority. Conversely, learning activities having no real-time implications and no affect on user's safety and experience (e.g. pre-lecture notes, review activities, graphical notes representation) are considered generic with low priority.

\subsection{Service Interaction Monitoring}

This component handles the interaction between mobile learner users and learning service activity. In which, the suitable resource delivery method is defined based on users' learning service type and on the communication technology being utilized. Three learning service delivery modes can be considered that are; group learning mode, where learning resources are distributed to a collaborative learning community. Server-based mode, where learners are connected to a remote server holding required learning resources. Peer-to-peer mode, in which two peer of learners are directly connected for sharing learning resources.

\subsection{Position Performance Monitoring}

Learner's location information is considered as the primary factor for describing the learning context and disseminating the required services accordingly. The availability of location information is dependent on the navigation technology enabled in the mobile device being utilized. Advanced level of positioning performance is needed to achieve precise description of learning service area and surrounding context. This is achieved using augmentation techniques such Assisted GPS (AGPS), and Differential GPS (DGPS) (Filjar et al., 2007). The required level of positioning performance is related to learning service type and users constraint level. Subsequently, the received learning service quality is highly dependent on the accuracy and precision of the location information being measured.

Table 3. Learning service types Vs Positioning performance levels (Alnabhan, 2009)

\begin{tabular}{ccclcc}
\hline $\begin{array}{c}\text { Learning Service } \\
\text { Types }\end{array}$ & $\begin{array}{c}\text { Position Performance } \\
\text { Levels }\end{array}$ & $\begin{array}{c}\text { Position Error } \\
(95 \%)\end{array}$ & Service Availability & $\begin{array}{c}\text { Position Reporting } \\
\text { Rate (PRR) }\end{array}$ \\
\hline Generic & High & $<=2 \mathrm{~m}$ & $\begin{array}{l}\text { Number } \\
\text { Satellites }>=7\end{array}$ & of & high frequency \\
& & & EGNOS & GEO $>$ & \\
& & & $80 \%$ & & \\
Specific & Moderate/Low & Variable & Variable & regular/low frequency \\
\hline
\end{tabular}

It is difficult to determine specific thresholds for required positioning performance. However, considering reported results in (Ott et al., 2005; Alnabhan et al., 2010), it is possible to define approximate performance levels thresholds, see Table 3. Three factors are used to identify the performance levels, known as accuracy, availability, and PRR. Best achievable factor values are associated with high performance level, and are assigned to specific learning services. Conversely, generic services are assigned with low or moderate position performance level.

The positioning performance level factors are described as follows:

- Position Accuracy: this factor is used to measure the required level of correctness in the measured position. As shown in Table 3, the moderate and low levels of position performance were not determined. However, an initial error threshold $(<=2$ meter) was assigned to be applicable for high learning service levels.

- Service Availability: this factor is used to describe the availability of positioning service or augmentation service during the navigation process. The availability plays an important role in affecting measured position accuracy and is dependent on satellite coverage challenges in particular geographical areas. 
- Position Reporting Rate (PRR): this factor is used to determine the location information sampling rate, which is dependent on learning style and service interaction level. PRR plays a significant role in the achieved position performance.

\subsection{Context Adaptation and Service Delivery}

As described in Figure 2, the predefined functional approach is used to generate a set of contextual factors having direct affect on providing the learning service. This includes the following factors:

- Learning service area.

- Learning service type.

- Learning service interaction level.

Learning service area is used to understand up-to-date information about surrounding context, and allows for constructing location-based learning resources. Learning service type indicates the service requirements and positioning performance levels. The service interaction level allows determining most suitable delivery method, used for delivering learning recourses according to defined service area.

\section{Evaluation Methodology and Results}

A preliminary evaluation experiment was conducted to measure the effect of position information accuracy on understanding surrounding learning context, and on interacting with the learning activity. This experiment allows learners to share their individual experiences and knowledge after interacting with specific locations within a specified path. The first step of the experiment is described as learning content authoring, in which a field trip was chosen within Jerash University campus. Three learning stations A, B, and C were selected along the field trip. Each learning station was placed on an open space position near to a faculty main gate. The location of each station was accurately determined and documented electronically on a digital map, to be easily accessed later on by participated learners. In addition, relevant information about each station surrounding context are collected and processed as learning resources associated to the station. These resources consisted of photos, notes, descriptions, and were created using mobile devices and mobile authoring applications. The allocation of these resources to a station was done by matching the location information of the resource to the location of the station.

In the second step, a group of students were asked to go through the predefined field trip, using the map being constructed in the previous step, along with their mobile devices having enabled GPS functionality. During this trip, students were asked to visit learning stations marked on the map, and were required to log location information for each station, and answer questions related to the context of these stations. Questions included defining faculty gate names or numbers, describing surrounding objects (e.g. trees, signs and parking lots), and defining any policy, rule, or announcement being advertised near to the marked station. Students will note question answers in their mobile devices. In the last step, information stored by learners during the trip are retrieved and assigned to respective marked learning stations. The accuracy of student logged location information was computed, and then linked to the correctness of students answers at each station. This allows for quantifying the relationship between the position information accuracy and understanding location-based learning contents.

During the content authoring step, U-Blox ANTARIS 4 GPS module with LEA-4T sensor was used for fixing accurate GPS coordinates for learning stations, and attaching them into a digital map. This GPS engine consists of 16 tracking channels, providing highly sensitive measurements and precise timing (U-Blox, 2003). In addition, this GPS module supports DGPS functionality, and was connected to a Dell XPS (core i3) laptop via a USB connection. The coordinates achieved in this step were used as reference values for computing position measurements accuracy achieved during students field trips. Position measurements at learning stations were conducted using standard GPS functionality embedded in students' mobile devices. Hence, the average of horizontal position accuracy achieved at the first learning station (A), was 3.6 meters at $95 \%$ confidence level. In addition, the average of horizontal position accuracy at station $\mathrm{B}$, and station $\mathrm{C}$ was 4 meters; and 2.0 meters respectively, computed at $95 \%$ confidence levels. Accordingly, the worst position accuracy was achieved at station $\mathrm{B}$, which was due to the environmental effects and limited satellite availability required for fixing the position at that location.

The correctness level of students' answers to the location-based questions was based on the accuracy of position fixing at the learning station. Hence, students at learning station $\mathrm{C}$ were able to be situated very close to the predefined station location, and have provided more precise answers to the context-related questions, especially while defining announcements available at the learning station. This simply confirms the significance 
relationship between the position information accuracy and location-based learning process. This relationship has an advanced effect after considering learning service types and its associated sensitivity to position error as being described in table 3 . The achieved position accuracy in the preliminary experiment only matches the generic learning service requirements. Position accuracy level $(<2$ meters) required for specific learning services can be achieved using position augmentation techniques available at the learning service centre.

\section{Conclusion}

This paper has presented a new m-learning functional approach responsible for providing adaptive learning services, taking into consideration a set of context factors described as learning service area, learning service type, and service interaction level. This paper has focused on learners' location information as a main factor affecting the performance of learning service delivery and learning context understanding. In addition, tolerance to positioning errors (accuracy level) was used to classify learning services into two types generic and specific. Generic are not affected by errors in location determinations, however specific services are considered crucial and highly affected by position errors. A preliminary evaluation experiment was performed measuring the relationship between positioning accuracy and the correctness level of learners 'answers to location-based context questions. This experiment consists of three main steps; the first one is described as learning content authoring, and the second includes field trip measurements conducted by participating students. In the last step, students' answers are analyzed and position accuracy of logged location information was computed. Results have shown that correctness and precision of students' answers were significantly affected by the accuracy of position fixing at each learning station. In future work, mobile technology performance will be considered within the measurement and evaluation procedures. This element is considered as important component required for the successful implementation of the proposed model.

\section{References}

Alnabhan, M. (2009). Adaptive, Reliable, and Accurate Positioning Model for Location-Based Services. PhD Thesis, Brunel University, November, 2009.

Alnabhan, M., Almasri, S., Garaj, V., Balachandran, W., \& Hunait, Z. (2010). Client-Server Based LBS Architecture: A Novel Positioning Module for Improved Positioning Performance. International Journal of Handheld Computing Research, 1(3), 1-18. http://dx.doi.org/10.4018/jhcr.2010070101

Arrigo, M., \& Ciprì, G. (2010). Mobile Learning for All. Journal of the Research Center for Educational Technology (RCET), 6(1), 94-102.

Ardito, C., Pederson, T., \& Costabile, M. F. (2006). CHAT - Towards a general-purpose infrastructure for multimodal situation-adaptive user assistance. International Workshop on Modelling and Designing User Assistance in Intelligent Environments (MODIE 2006). In T. Pederson, H. Pinto, M. Schmitz, C. Stahl \& L. Terrenghi (Eds.), Saarbruecken (pp. 27-31). Germany: Saarland University.

Barbieri, T., Bianchi, A., Carella, F., Ferra, M., \& Sbattella, L. (2005). MultiAbile: A multimodal learning environment for the inclusion of impaired e-Learners using tactile feedbacks, voice, gesturing, and text simplification. In proceeding of Assistive Technology Shaping the Future, Lille, France.

Chen, C. M., \& Li, Y. L. (2010). Personalized context-aware ubiquitous learning system for supporting effective English vocabulary learning. Interactive Learning Environments, 18(4), 341-364. http://dx.doi.org/10.1080/10494820802602329

Fallahkhair, S., Pemberton, L., \& Griffiths, R. (2007). Development of a cross-platform ubiquitous language learning service via mobile phone and interactive television. Journal of Computer Assisted Learning, 23, 312-325. http://dx.doi.org/10.1111/j.1365-2729.2007.00236.x

Filjar, R., Bušic, L., \& Kos, T. (2007). A Case Study of DGPS Positioning Accuracy for LBS. Automatika, 48(1-2), 53-57.

Huang, Y. M., Kuo, Y. H., Lin, Y. T., \& Cheng, S. C. (2008). Toward interactive mobile synchronous learning environment with context-awareness service. Computers \& Education, 51, 1205-1226. http://dx.doi.org/10.1016/j.compedu.2007.11.009

Hsiao, H. S., Lin, C. C., Feng, R. T., \& Li, K. J. (2010). Location Based Services for Outdoor Ecological Learning System: Design and Implementation. Educational Technology \& Society, 13(4), 98-111.

Lan, Y. J., Sung, Y. T., \& Chang, K. E. (2009). A mobile-device-supported peer-assisted learning system for collaborative early EFL reading. Language Learning \& Technology, 11(3), 130-151. 
Ott, B., Wasle, E., Weimann, F., Branco, P., \& Nicole, R. (2005). Pedestrian Navigation in Difficult Environments: Results of the ESA Project SHADE. In P. Oosterom, S. Zlatanova \& M. Fendel (Eds.), Geo-information for Disaster Management (pp. 1113-1126). Springer Berlin Heidelberg. http://dx.doi.org/10.1007/3-540-27468-5_77

Rensing, C., Tittel, S., \& Steinmetz, R. (2012). Location-Based Services for Technology Enhanced Learning and Teaching. Software Service and Application Engineering (pp. 165-180). Springer. http://dx.doi.org/10.1007/978-3-642-30835-2_11

Richter, K. F., Abrams, D., \& Raubal, M. (2010). Navigating and Learning with Location Based Services: A User-Centric Design. In 7th International Symposium on LBS \& TeleCartography (LBS2010), Gouangzhou, China, 20-22 September 2010.

Sharples, M., Sánchez, I. A., Milrad, M., \& Vavoula, G. (2009). Mobile Learning: Small devices, big Issues. Technology-Enhanced Learning, Part IV (pp. 233-249). http://dx.doi.org/10.1007/978-1-4020-9827-7_14

So, H., Tan, J., \& Tay, J. E. (2012). Collaborative mobile learning in situ from knowledge building perspectives. Asia-Pacific Education Researcher (De La Salle University Manila), 21(1), 51-59.

Ternier, S., \& Börner, D. (2011). ARLearn - interaktive Unterstützung ortsbasierter,mobiler Lernak-tivitäten. Retrieved from http://www.httc.de/ws-mobile-learning

Tan, E., \& So, H. J. (2011). Location-based collaborative learning at a Geography trail: Examining the relationship among task design facilitation and discourse types. In proceeding of 9th International Conference on Computer Supported Collaborative Learning (CSCL), Hong Kong, China, 4-8, July 2011.

U-Blox. (2003). LEA-4T GPS Receiver Module Datasheet, Application Notes. Document ID GPS.G4-MS4-05069

Wu, P. H., Hwang, G. J., Su, L. H., \& Huang, Y. M. (2012). A Context-Aware Mobile Learning System for Supporting, Cognitive Apprenticeships in Nursing Skills Training. Educational Technology \& Society, 15(1), 223-236.

\section{Copyrights}

Copyright for this article is retained by the author(s), with first publication rights granted to the journal.

This is an open-access article distributed under the terms and conditions of the Creative Commons Attribution license (http://creativecommons.org/licenses/by/3.0/). 